\title{
KIMA: Noise: A visual sound installation on urban noise
}

\author{
Oliver Gingrich \\ Bournemouth University, UK \\ olivergingrich@hotmail.co.uk
}

\author{
Evgenia Emets \\ Artist, Portugal \\ emetsjane@gmail.com
}

\author{
Alain Renaud \\ Bournemouth University, UK \\ alain.renaud@mintlab.ch
}

\author{
Stephen Stansfeld \\ Queens Mary, London, UK \\ s.a.stansfeld@qmul.ac.uk
}

\begin{abstract}
KIMA: Noise is a participatory art piece inviting audiences to explore impact of urban noises interactively. Using specific urban sound sources, the audience experiences noise as spatial soundscapes, responding to it, physically engaging and interacting with it. KIMA: Noise creates awareness for the phenomenon of noise pollution. The paper looks at preeminent research in the field, and draws conclusions of how sound affects us as individuals. The art project KIMA: Noise is introduced technically and conceptually.
\end{abstract}

Visual sound. Participatory art. Visual sound installation. Noise pollution.

\section{KIMA: VISUAL SOUND}

Sound is a complex phenomenon, which can be experienced physically, mentally, emotionally, but also visually. KIMA is an ongoing quest for the art collective Analema Group to push the boundaries of visual and sound art through audience participation. We engage audiences to explore their voices through the synaesthetic connection of senses and the science of sound.

Co-creation of sound is encouraged through realtime visual expression of minute differences in sound input. The project enables collaborative participation in the process of sound creation and listening. KIMA invites audiences to explore how sound can be connected to the physical world, but also to imagine visual interpretations of sound.

\subsection{KIMA: Noise context engineering}

London is a major city. It has noise problems just like any other large metropolitan area. This noise pollution affects people in day-to-day life. Ranging from unconscious effects generated by the nuisance of traffic to airplane hums, noise pollution disrupts everyday life. Although a multitude of noise sources contribute to this urban noise pollution, an ordinary citizen might only be aware of a general hum, blending each individual sound into single stream of white noise. Such urban soundscapes of noise pollution often blend with really loud sounds such as produced by large jets at airports - with direct consequences for the people affected by it. This research paper looks at the science of noise pollution, its effect on social behaviour (Cohen \& Spacapan 1984) and health (Stansfeld 2012). In our paper, we will discuss on-going research into the psychology of noise, the effect of noise pollution, as well as strategies in contemporary sound art to tackle this subject.

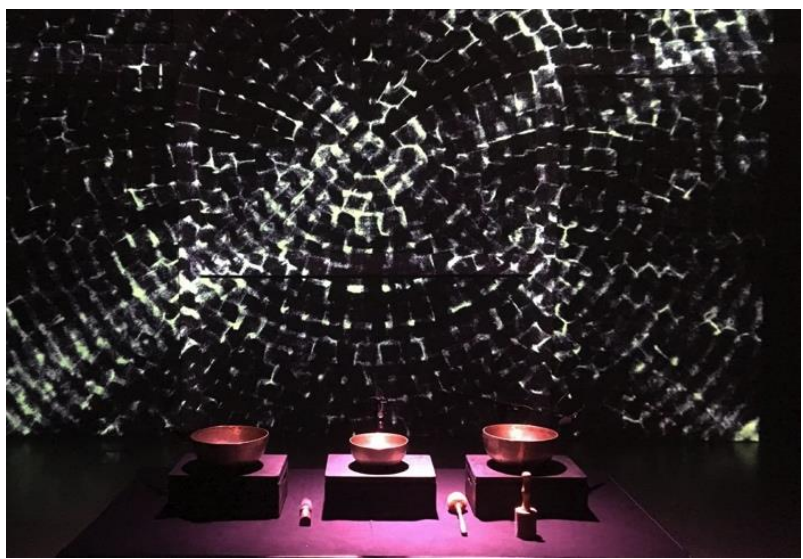

Figure 1: Projection of KIMA - The Wave at Fondation L'Abri.

Furthermore, we will present our on-going development of KIMA: Noise. KIMA: Noise invites audiences to experience an 'ocean of sounds' surrounding them daily in a completely new way. Consciously becoming aware of the sources of these sounds, the audience connects with noise creatively by playfully rearranging such sounds into a new audio-visual composition. For EVA London, we will present a demo of the piece; recording noise close to such strategic points for instance airports, freeways, and main landmarks. We will 
work with different types of sounds and let the audience engage with sounds they were previously unaware of. The audience will explore a visual representation of different types of noises. At EVA a demo of these representations will be presented as a first prototype, as a site-specific projection, which we are planning to showcase as work in progress of the final piece.

\section{PHYSICALITIES OF SOUND}

Noise is understood as irritating, "undesirable", disturbing sound - a subjective categorisation of sounds that follows certain key criteria and thresholds. Sound itself consists of waveforms detected by the sense of hearing (Georgiejevic 2005) that is defined by its frequency and amplitude. The human ear in its less affected state can detect frequencies ranging from 20, 20,000 hertz. A-weighting, which measures relative loudness as perceived by human ear, is commonly used to measure noise and sound pressure levels. Noise is categorised according to a sound's intensity, i.e. the amount of sound energy transcending a surface area unit (Vuvic \& Ivanovic 2000). Intensity is measured logarithmically in decibel $(\mathrm{dB})$ to account for characteristics of the human ear, which doesn't respond to sound intensity linearly. The threshold of hearing is set with $0 \mathrm{~dB}$, whereas the threshold of pain is commonly defined as $120 \mathrm{~dB}$. Noise is generally defined as an undesirable sound, a pollutant of the environment. Sound levels from over $55 \mathrm{~dB}$ are generally experienced as unpleasant - at the threshold of annoyance. Noise in the vicinity of airports can exceed $90 \mathrm{~dB}$, with severe impacts on health.

\subsection{Noise impact on health}

Studies have shown that noise impact on sleep patterns can occur at levels louder than $65 \mathrm{~dB}$ in sensitive people, leading to anxiety, irritation and other symptoms of sleep deprivation (Korica, Popovic 2017). The most frequent response to environmental noise is annoyance, mild anger and feelings of intrusion into privacy (Guski et al. 2017). Prolonged exposure to noise levels of $90 \mathrm{~dB}$ and above, usually in occupational settings, can cause serious hearing damage and neurovegetative problems. Excessive noise exposure can furthermore have an effect on the endocrine and immune systems including decrease in immunity to infections, and heightened propensity to develop allergies and a weakened autoimmune system (Ermolaev 2017). Other effects of excessive noise exposure include headaches, memory impairment, undue fatigability, somnolence, sleep disturbances, emotional instability, hyperhidrosis and chest pain (ibid.) Road traffic and aircraft noise have shown to be related to increased blood pressure and a small increased risk of myocardial infarction in adults (Basner et al. 2014).

\subsection{Noise effect on attention}

Multiple experiments of the 1970s and beyond point to a persistent link between aggression and noise (Konecni 1975, Donnerstein \& Wilson 1976). A large body of research that suggests that chronic noise exposure influences human performance (Stansfeld 2000). Noise exposure is associated with attention and learning deficits, delays in reading comprehension and performance on standardised reading tests (Stansfeld et al. 2005). A study on $7-11$ year olds in Barcelona by Dadvand, Forns et al. (2016) shows that exposure to noise at school results in higher degree of behavioural problems. Research by Clark, Sibhi et al. (2017) shows a positive correlation between exposure to traffic noise, air pollution and diabetes. This cohort-study, which took place over five years in Vancouver, conducted on over 350,000 people shows a strong interrelation between noise pollution exposure and metabolic health including diabetes. More than 20 studies have shown a link between noise level and children's reading and memory capabilities (Stansfeld 2010).

\subsection{Noise effect on social behaviour}

A large body of research points to the effect of noise on social behaviour: As high noise levels are directly linked to the growth of urban areas, and metropolitan areas are ever expanding, noise pollution is on the rise. Milgram (1970) demonstrated human shortcomings to help others in noisy environments. Studies by Mathews and Conan (1975) comparing the impact of noise support this hypothesis. Multiple experiments by Page (1974) further support the fact that the propensity to help decreases as noise levels increase. This series of experiments involved a subject in need of help under noisy conditions (noise levels higher than $85 \mathrm{~dB}$ ) and showed that the propensity to help was less pronounced under noisy conditions. The likelihood to help decreased even after the exposure to noise had taken place as studies by Sherrod and Downs (1974) indicate. An experiment by Korte and Grant (1980) showed that pedestrians in noisy areas had more difficulties with recollection as noise diminished attention. Studies by Cohen and Lezak (1977) further support the idea that memory and attention is hindered through the impact of noise. Interestingly, the degree of control a participant has over noise exposure influences the degree they are negatively affected by it (Cohen 1980). Accordingly, with KIMA: Noise, we aim to re-establish a sense of control over noise exposure by raising awareness, through direct interaction with the art installation and active engagement. 


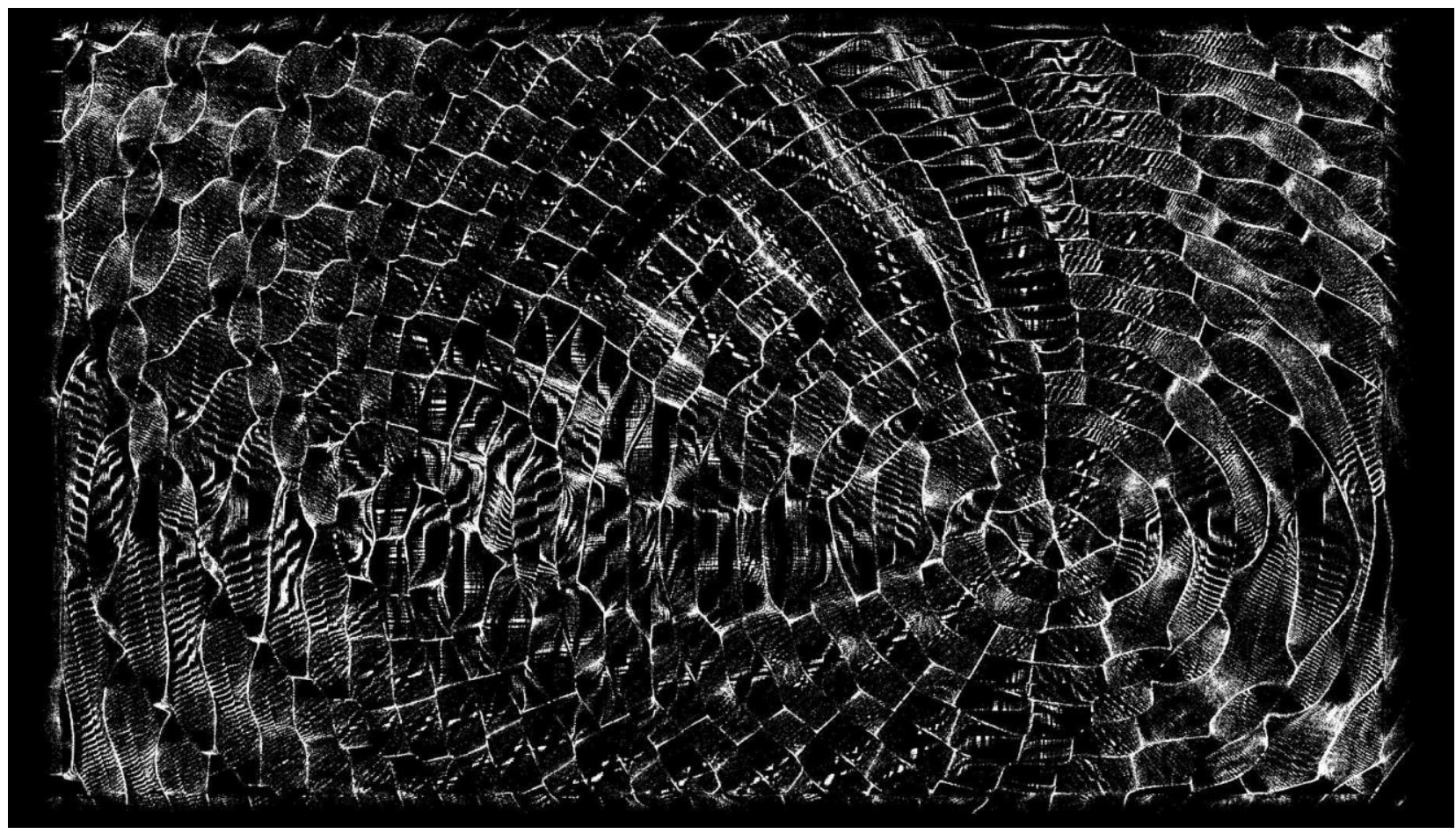

Figure 2: KIMA - The Wave.

\section{RETHINKING NOISE AS SOUND}

A number of studies suggests a link between perceived control over noise and the resulting tolerance to the effect of noise: An experiment by Donnerstein and Wilson (1976) showed that postnoise exposure resulted in heightened levels of aggressions, except when subjects perceived to be in control over noise, in which case the side effects were less severe. Experiments on the impact of noise on propensity to help behaviour (Sherrod and Downs 1974), as well as on performance (Cohen 1980, Glass and Singer 1972) - all point to the persistent relationship between control and the cancellation of negative impact of noise (Jones \& Chapman 1984).

With Analema Group, we utilise this knowledge in the pursuit of giving our audiences control over noise experiences. Using direct interaction, the audience explores sound visually, creatively and spatially all the while listening, interfering and engaging with noise, controlling it. The art and research project KIMA has a six-year long history, of creating immersive sound and visual experiences for our audiences.

\subsection{KIMA as visual sound}

KIMA originated in the quest to explore the boundaries between sound and vision artistically and creatively. Investigating visual and physical properties of sound, on a mathematical, physical and experiential level, Analema Group orchestrates experiences that bring the audience closer to an otherwise intangible phenomenon. With KIMA, sound can be felt - for instance at Fondation L'Abri as a physical standing wave.

Alternatively, sound can be visually explored, as we demonstrated at the London Roundhouse, where the audience experienced sound visually with the help of computer visualisation. Last but not least, sound can be experienced as an immersive realtime interface for shared music experiences as performed at the Union Chapel in 2015.

With KIMA: Noise, we are tackling real, physical impact of sound in urban environments, by creating a new tool for raising awareness. Conceptually we will explore the notion of noise being 'unwanted sound' (quoting Garret Keizer). We are looking at the totality of sounds and noises and an 'acoustic atmosphere' - sounds that we prefer to ignore unmusical sounds. 


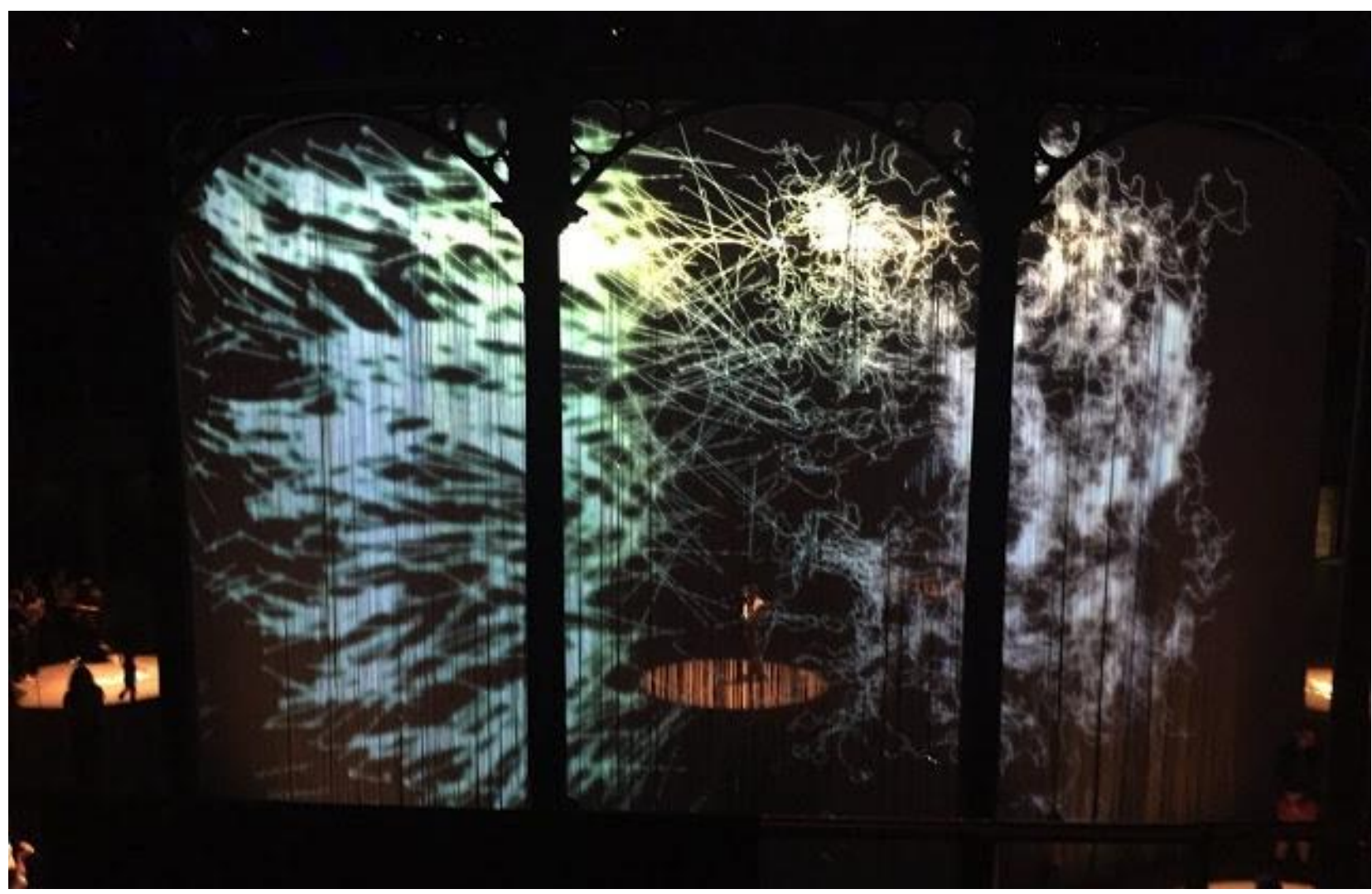

Figure 3: KIMA: The Wheel-Roundhouse, Curtain Call, 2016.

Echoing Murray Schafer's credo that 'Noise pollution results when man does not listen carefully', we will deconstruct the "noises" around us, to create new awareness and engagement with urban sounds. With KIMA: Noise, we will create an immersive environment where the audience discovers noise through listening, visually as well as through interaction. With this development, we bring a new awareness of its richness before the judgement of its aesthetics.

\subsection{Geometric spatial sound experience}

Noise is crucial for our survival: When our ancestors lived in caves, they explored unknown landscapes, relying on sound cues of environmental noise. Our modern ears are growing increasingly deaf to urban noises due to 'oversaturation' of present day city noises, which we all ultimately contribute to - knowingly or unknowingly. We become increasingly disoriented by the endless bombardment of noises, when we are awake and when we are asleep. The project is developed in collaboration with Stephen Stansfeld, one of the leading researchers in the effects of noise on human health.

From the outset, KIMA was designed as an intelligent, responsive system that allows to interact with sound visually and crucially spatially.
Audiences connect with sound on a physical level, overcoming barriers of entry through an intuitive and often immersive interface. At the Roundhouse, this took the shape of an immersive sound and visual participatory performance piece on Ron Arad's Curtain Call.

Visual and sound waves encircled audience repeating the geometry of circular space. With KIMA: Noise, sound waves will be experienced spatially, as an architecture of audible and visual sound, that the audience can experience by traversing the room. A sound sculpture that has a physical position in space invites the audience to find their own physical relationship with noise.

Furthermore, the audience is invited to draw graphic scores, which will then be transformed into a spatial movement of sounds audibly moving across the space. We have implemented spatial ambisonic sound installations in our previous projects at the Roundhouse in London and at L'Abri Fondation in Geneva. However, the use of this graphic element is novel and will be developed specifically with audience participation in mind. We are interested in the spatiality of sound experience and find inspirations in the works by Bernhard Leitner and Janet Cardiff among others. 


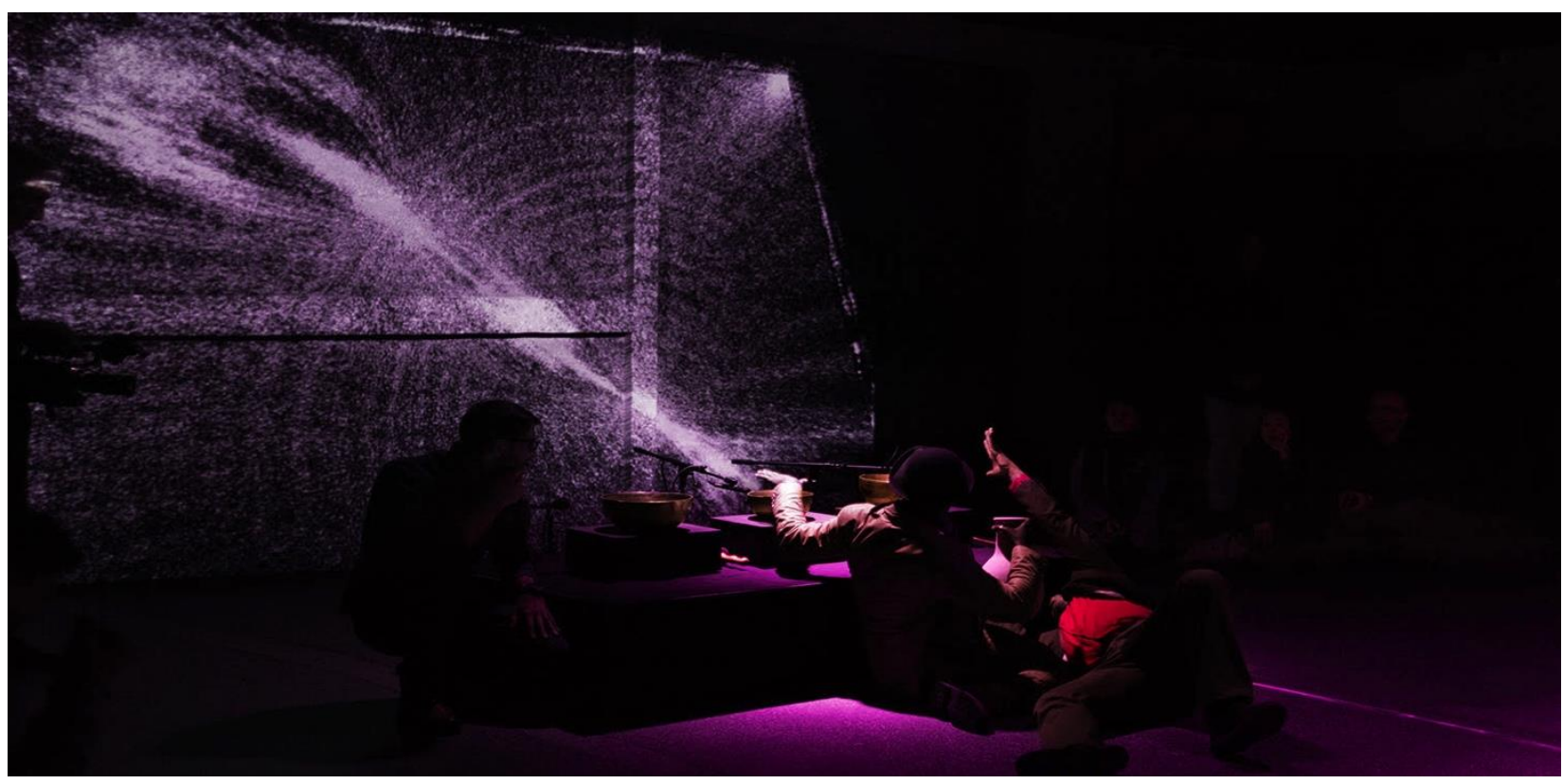

Figure 4: KIMA: The Wave at Fondation L'Abri, Geneva, 2016.

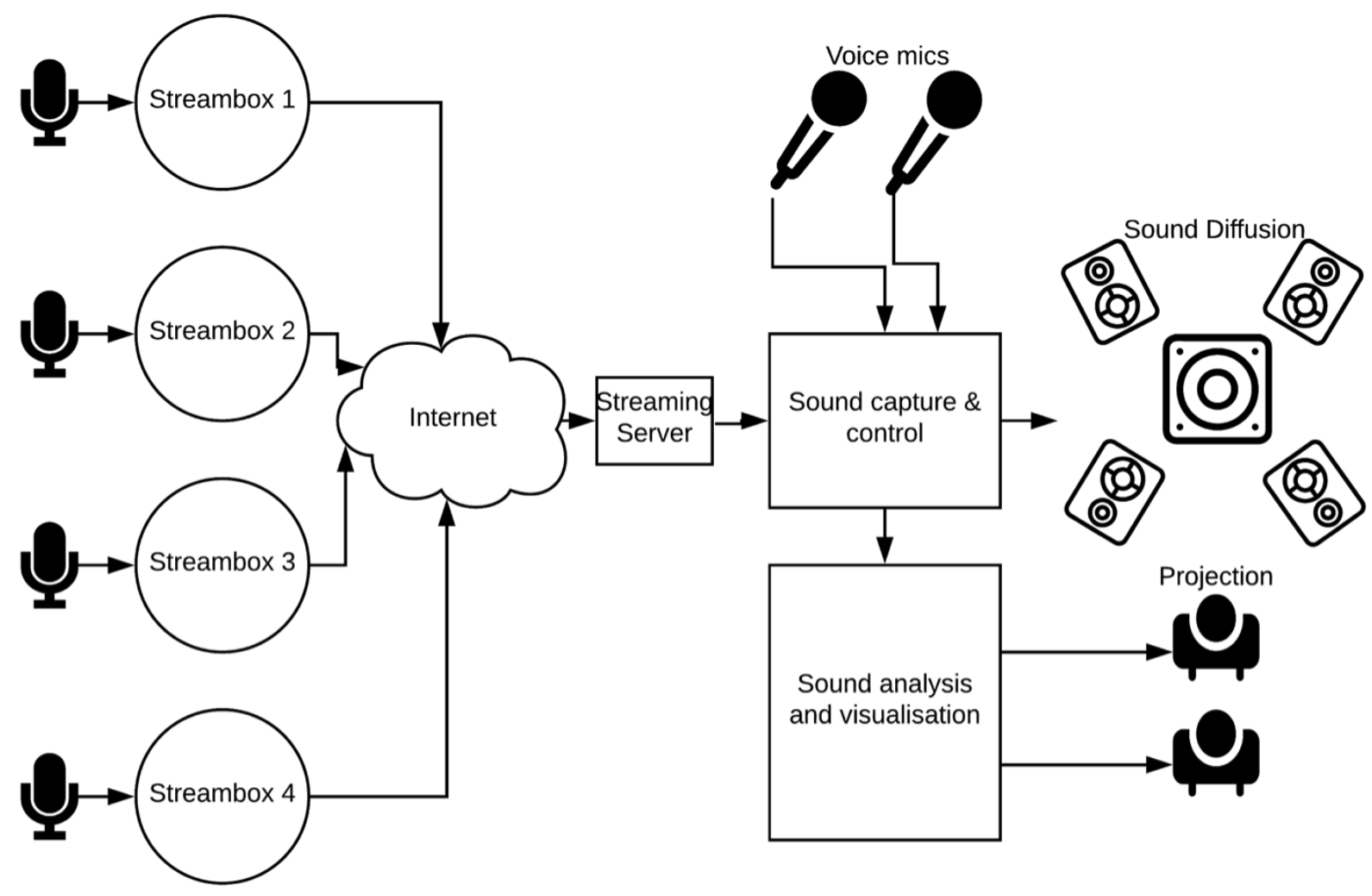

Figure 5: KIMA: Noise - Technical Schematic. 


\section{KIMA: NOISE - INSTALLATION}

Microphone stations will capture sounds from the installations direct urban environment and display it as an immersive surround sound installation within the space of the exhibition. External, urban sounds will be displayed spatially as a 3-dimensional, invisible sound sculpture. Noise will travel through the space, for the audience to discover sonically and spatially.

A visual representation of sounds, drawn from the immediate vicinity of the exhibition's urban environment will be projected within its context. Projections of visual sound interpretation invite the audience to re-contextualise noise. These projections will display representation of sounds occurring on the outside to be seen inside the space of the exhibition. Projection as refraction will allow the audience to re-contextualise sound, from background "white noise" into specific, meaningful echoes of the urban arena, allowing the audience to engage interactively.

Analema Group will invite the audience to participate in the creation of a spatial composition by drawing trajectories of sounds. Affecting the movement of sound in the space, the audience can observe the noise surrounding us, visually, spatially and acoustically. At the later stage of project development, it will be possible for the audience to contribute with their own recordings of noises from the city, which will be woven into the overall composition.

\subsection{KIMA: Noise as participatory performance}

The act of engagement as a shared experience is a key element of any project by Analema Group. The audience thereby becomes co-author of the piece, contributing to a joined, sonic and visual composition. At the KIMA: The Wheel performance at the Roundhouse, the audience was invited to participate with their voices. At Incloodu Festival, the deaf community actively created sounds, and observed their visual representation in real-time. With KIMA: Noise, we actively invite the audience to create noise, whether with their voices or by any other means, thereby influencing and controlling the impact of noise.

We propose to install microphones and audio streaming boxes around the city in strategic noiseproducing environments (and where technology and ubiquitous communication allows) - for example, sound of construction site, trains, traffic sounds. We will measure and record noise close to such strategic points and stream these sounds in real-time in the space through an array of speakers.

We will work with a spectrum of noise and frequencies and let the audience actively engage with sounds they were previously not consciously aware of. From really low hums and even inaudible sounds, vibrations we can only feel, through midtones to the upper levels of our hearing range - we will harness noises and weave them into a new composition. The audience becomes aware of the role of noises in their lives. We will project real time captured sounds from the city back into the space and create a visual representation of different types of noises for an immersive visual environment.

By interacting with these sounds, modulating them, drawing them, but also interfering with them, the audience regains a sense of awareness, a sense of control and with it - redefines noise from unwanted sound, into a desired sound and visual scape.

\section{FUTURE \& OUTLOOK}

The audience will be invited to explore this relationship interactively, using microphone interfaces and a visual display that allows for direct feedback on the physicality of sound. The audience will have the chance to interact with the KIMA: Noise installation through these microphones as well as the graphic scores and encounter an immersive soundscape resulting from their interactions. They will learn about the physics of sound and participate in the creation of a live artwork as a joined, shared experience.

KIMA: Noise draws attention to a persistent problem in metropolitan areas, one often neglected by politicians and local communities. By encouraging a new form of sensitivity, the audience reconnects with their urban environment. As preeminent research has shown, a sense of control compensates for effect and impact of noise, results in a new form of immunity. We are not going so far to suggest that this is what we are aiming for, but reconnection with our context, a new-found engagement can only help our audiences to reconnect with the city and its sounds.

With KIMA, we will continue to push the boundaries of perceptions of sound. Whether through the use of artificial intelligence, further exploration of spatial sound experiences, research into physical and intangible wave-phenomena, the project will maintain its focus on participatory and immersive art, which puts the audience at the centre of the creation process. 


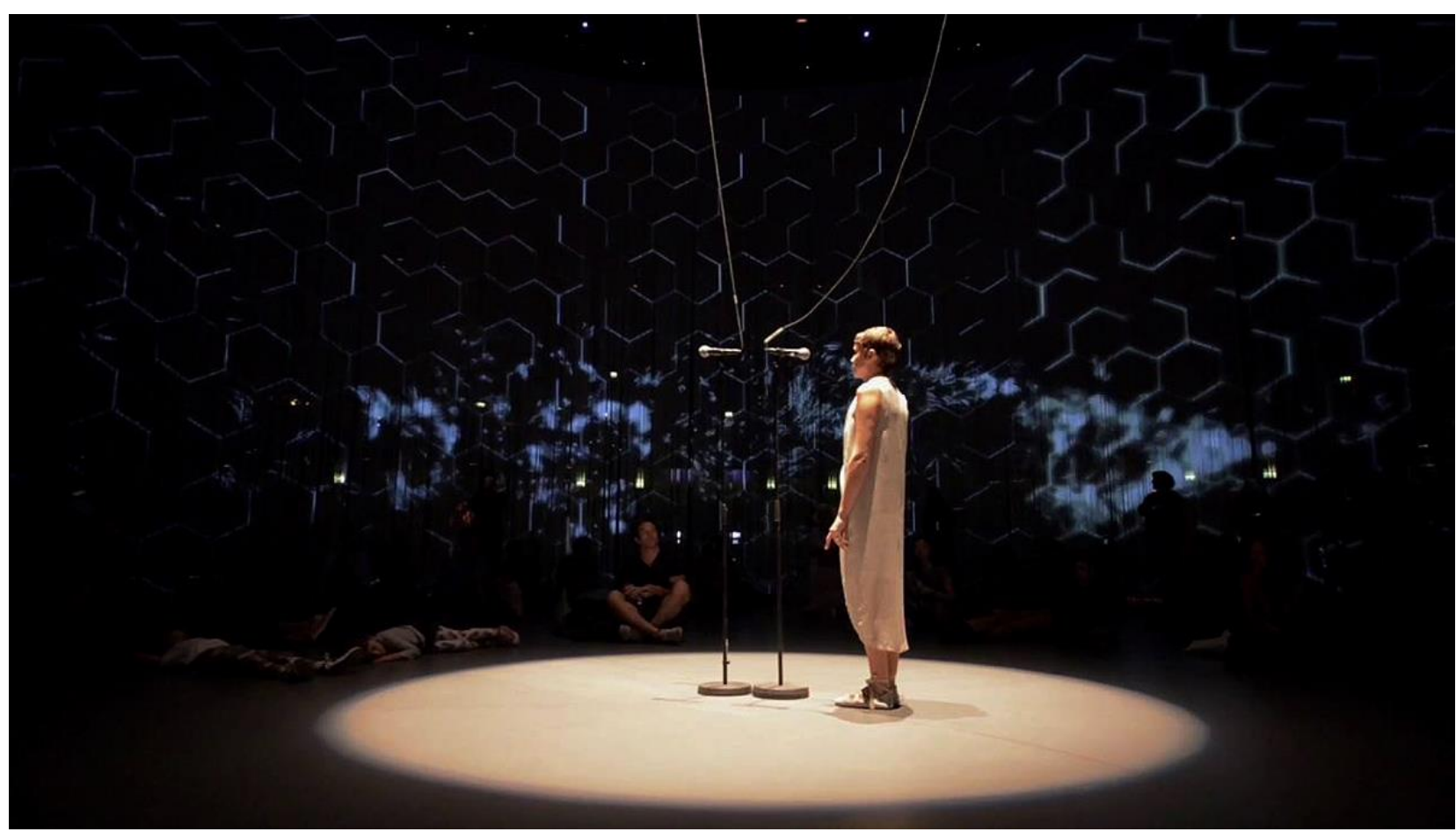

Figure 6: KIMA: The Wheel - Roundhouse 2018.

\section{REFERENCES}

Basner, M., Babisch, W., Davis, A., Brink, M., Clark, C., Janssen, S., and Stansfeld, S. (2014) Auditory and non-auditory effects of noise on health. Lancet, 383(9925), pp.1325-1332.

Clark, C., Sbihi, H., Tamburic, L., Brauer, M., Frank, L. D., and Davies, H. W. (2017) Association of long-term exposure to transportation noise and traffic-related air pollution with the incidence of diabetes: A prospective cohort study. Environmental Health Perspectives, 125(8), pp. 087025. DOI: $10.1289 / \mathrm{EHP} 1279$

Cohen, S. (1980) Cognitive Processes as Determinants of Stress. In: I. Sarason and C. Speilberger (eds.), Stress and Anxiety Vol VII, Washington, DC, Hemisphere Press.

Cohen, S., and Lezak, A. (1977) Noise and inattentiveness to social cues, Environment and Behaviour, 9, pp.559-572.

Cohen, S., and Spacapan, S. (1984) The Social Psychology of Noise. In: Jones, D. M. and Chapman A. J. (eds.), Noise and Society, London, Wiley.

Donnerstein, E., and Wilson, D. W. (1976) Effects of noise and perceived control on ongoing and subsequent aggressive behaviour. Journal of Personality and Social Psychology, 34, pp.774781.
Ermolaev, A. (2017) Methods of Evaluating Noise Pollution in the Megalopolis. In B. Katalinic (ed.), Proceedings of the 28th DAAAM International Symposium, pp.926-929.

Dadvand P., Nieuwenhuijsen M. J., Esnaola, M. Forns, J., Basagaña, X., and Alvarez-Pedrerol, M. (2015). Association between traffic-related air pollution in schools and cognitive development in primary school children. Proceedings of National Academy of Sciences of the United States of America, 523, pp.59-63.

Georgijević, V. et al., (2005) Predavanja iz fizike, Univerzitet u Begradu - Građevinski fakultet, Beograd, pp.279-293. (In Serbian.)

Glass D. C, and Singer, J. E.(1972) Urban Stress: Experiments on Noise and Social Stressors, New York, Academic Press.

Guski R., Schreckenberg D., and Schuemer R. (2017) WHO Environmental Noise Guidelines for the European Region: A Systematic Review on Environmental Noise and Annoyance. International Journal of Environmental Research and Public Health, 14(12). DOI: 10.3390/ijerph14080873

Jones, D. M., Chapman A. J., and Auburn, T. C. (1982) Perceived Control in Continuous Loud Noise. Current Psychological Research, 2, p.111. DOI: $\underline{10.1007 / B F 03186751}$

Konecni, V. J. (1975) The mediation of aggressive behaviour: arousal, anger and cognitive labeling. 
Journal of Personality and Social Psychology, 32, pp.706-716.

Korica, S., and Popovic, K. (2017) Noise, Sources of Noise and its Influence on the quality of work and living environment. University Union - Nikola Tesla, Faculty for Ecology and Environmental Protection, Serbia.

Korte, C., and Grant, R. (1980) Traffic Noise, Environmental Awareness, and Pedestrian Behaviour, Environment and Behaviour, 12, pp.408-420.

Milgram, S. (1970) The Experience of Living in Cities, Science, 13, pp.1461-1468.

Page, R. A. (1974) Noise and helping behaviour. Environment and Behaviour, 9, pp.311-334.

Schafer, M. R. (1977) The Tuning of the World, Knopf.
Sherrod, D. R., and Downs, R. (1974) Environmental determinants of altruism: The effect of stimulus overload and perceived control on helping. Journal of Experimental Social Psychology, 10, pp.468-479.

Stansfeld, S. A., Haines, M. M., Burr, M., Berry, B., and Lercher P. (2000) A review of environmental noise and mental health. Noise Health [serial online] (retrieved 15 March 2018).

Stansfeld, S. A., Berglund B., Clark C., LopezBarrio I., Fischer P., Ohrstrom E., et al. (2005) Aircraft and road traffic noise and children's cognition and health: a cross-national study. Lancet 2005;365(9475), pp.1942-1949.

Stansfeld, S., and Clark, C. (2012) Future environmental noise and health research needs for policy. The Journal of the Acoustical Society of America, 131(4), p.3295.

Vučić, V. M., and Ivanović, D. M., (2000) Fizika 1, IP „Nauka”, Beograd. 